\title{
BUDAYA ORGANISASI DALAM MENDUKUNG IMPLEMENTASI KNOWLEDGE SHARING DOSEN PADA PERGURUAN TINGGI NEGERI DI KOTA BANDUNG
}

\author{
Fahmi Jahidah Islamy ${ }^{1}$, Risris Nurjaman² \\ ${ }^{1}$ Program Studi Manajemen, Sekolah Tinggi Ilmu Ekonomi Indonesia Membangun, Bandung, Indonesia \\ ${ }^{2}$ Program Studi Teknik Industri, Fakultas Teknik, Universitas Langlangbuana, Bandung, Indonesia \\ fahmiislamy10@upi.eduํ․,risnur@upi.edu ${ }^{2}$
}

\begin{abstract}
Knowledge based view (KBV) is a new existence from the view of company resources and provides strong theoretical support for intellectual capital. Knowledge management (KM) comes with the concept of being able to manage intellectual capital in organizations. The practice and development of KM implementation in organizations continues to increase. Knowledge sharing is one of the core processes in KM and is closely related to the world of work of a lecturer. The successful implementation of knowledge sharing must be supported by an organizational culture that always influences each of these practices. The purpose of this study is to determine the organizational culture factors that can support the implementation of knowledge sharing of lecturers at State Universities (PTN) in Bandung. In this research the method used is a causal study and the sampling technique used is probability sampling. The sample taken was permanent PTN lecturers in Bandung. The number of samples was 119 lecturers. The analysis technique used is path analysis. The results showed that organizational culture significantly influenced the implementation of knowledge sharing.
\end{abstract}

Keywords: organizational structure; reward sistem; organizational culture; knowledge sharing

\begin{abstract}
Abstrak
Knowledge based view (KBV) merupakan eksistensi baru dari pandangan sumber daya parusahaan dan memberikan teoritis yang kuat dalam mendukung intellectual capital. Knowledge management $(K M)$ hadir dengan konsep untuk dapat mengelola intellectual capital dalam organisasi. Praktik dan pengembangan implementasi KM dalam organisasi terus mengalami peningkatan. Knowledge sharing merupakan salah satu proses inti dalam KM serta berkaitan erat dengan dunia kerja seorang dosen. Keberhasilan implementasi knowledge sharing harus didukung oleh budaya organisasi yang senantiasa mempengaruhi steiap praktik tersebut. Tujuan penelitian ini adalah untuk mengetahui faktor budaya organisasi yang dapat mendukung implementasi knowledge sharing dosen pada Perguruan Tinggi Negeri (PTN) di Bandung. Dalam penelitian ini metode yang digunakan adalah studi kausal dan teknik sampling yang digunakan adalah probability sampling. Sampel yang diambil adalah dosen tetap PTN di Bandung. Jumlah sampel adalah 119 dosen. Teknik analisis yang digunakan adalah analisis jalur (path analysis). Hasil penelitian menunjukkan bahwa budaya organisasi berpengaruh signifikan terhadap implementasi knowledge sharing.
\end{abstract}

Kata kunci: struktur organisasi; sistem penghargaan; budaya organisasi, knowledge sharing

Corresponding author: Email : fahmiislamy10@upi.edu

History of article : Received : Desember 2017 , Revised : Februari 2018, Published : April 2018 


\section{PENDAHULUAN}

Pendekatan KBV dapat membentuk serta membangun keterlibatan intellectual capital dalam organisasi. Saat ini telah memasuki knowledge era (Halawi et al., 2005), (Uhl-bien, Marion, \& Mckelvey, 2007) , (Gorey \& Dobat, 1996) pada era tersebut, pengetahuan merupakan sumber daya yang sangat bermakna (Ricceri, 2008). Perguruan tinggi merupakan organisasi pembelajaran yang pada akhirnya menghasilkan pengetahuan, yaitu tacit knowledge (pengetahuan yang terletak di otak seseorang) dan eksplicit knowledge (pengetahuan yang sudah di dokumentasikan).

Proses knowledge management menurut Probst et al dalam Tobing (2011), adalah: (1) Knowledge Identification; (2) Knowledge Acquisition; (3) Knowledge Development; (4) Knowledge Sharing/Distribution; (5) Knowledge Utilization; dan (6) Knowledge Retention. Salah satu proses Knowledge Management adalah knowledge sharing. (Al-Alawi, AlMarzooqi, \& Mohammed, 2007) memaparkan bahwa "Knowledge sharing is critical to a firm's successas it leads to faster knowledge deployment to portions of the organization that can greatly benefit from it". Hal tersebut senada dengan pendapat (Hendriks, 1999) yang mengatakan bahwa knowledge sharing terbukti menjadi penghalang yang signifikan terhadap efektivitas implementasi KM pada organisasi.

Knowledge sharing adalah proses dimana individu atau sekelompok orang saling berinteraksi berbagi pengetahuan dengan individu atau kelompok lain (Islamy, 2013), (Ipe, 2003). Knowledge sharing telah diidentifikasi sebagai fokus area utama dalam $\mathrm{KM}$, dimana dengan KM pengetahuan akan mencapai nilainya (kompetitif dan ekonomi) (Hendriks, 1999). Terdapat dua proses dalam knowledge sharing, knowledge collecting dan knowledge donating (Van Den Hooff \& Ridder, 2004), (van den Hooff \& de Leeuw van Weenen, 2004), (Islamy, 2013).

Menurut Gupta et al, dalam Tobing (2011), budaya organisasi yang dapat mendukung implementasi knowledge sharing mencakup enam kategori utama, yaitu: sistem informasi, SDM, proses, kepemimpinan, sistem penghargaan, dan strukur organisasi (Al-Alawi et al., 2007), (Islamy, 2013).

Perguruan Tinggi memiliki banyak pengetahuan yang berada dibenak SDM nya khususnya dosen, oleh karena itu agar dapat mendukung proses knowledge sharing pada perguruan tinggi dibutuhkan penelitian budaya organisasi agar dapat melihat faktor budaya organisasi yang mendukung implmentasi knowledge sharing tersebut. Serta dari data yang didapat melalui Web of Science dan Scopus, data tersebut menjelaskan bahwa peneliti Malaysia dan Thailand jauh lebih produktif dalam meghasilkan publikasi ilmiah internasional dibandingkan dengan peneliti di Indonesia. Dapat dikatakan bahwa implementasi knowledge sharing dosen masih belum maksimal, maka dari permasalahan tersebut peneliti tertarik untuk meneliti faktor budaya organisasi terhadap knowledge sharing.

Tabel 1. Perbandingan Publikasi Internasional di Indonesia pada Scopus

\begin{tabular}{|c|r|r|r|r|}
\hline Tahun & Malaysia & Thailand & Indonesia & Filipina \\
\hline $\begin{array}{c}\text { 2016 } \\
\text { (April) }\end{array}$ & 6.630 & 3.864 & 2.062 & 664 \\
\hline 2015 & 24.460 & 11.886 & 6.706 & 2.286 \\
\hline 2014 & 27.911 & 13.244 & 6.219 & 2.020 \\
\hline 2013 & 25.004 & 12.171 & 4.997 & 1.881 \\
\hline 2012 & 22.564 & 11.898 & 3.811 & 1.734 \\
\hline 2011 & 20.663 & 10.695 & 3.227 & 1.580 \\
\hline 2010 & 15.662 & 9.993 & 2.602 & 1.329 \\
\hline
\end{tabular}

Tabel 2. Perbandingan Publikasi Internasional di Indonesia pada Web of Sciance

\begin{tabular}{|c|r|r|r|r|}
\hline Tahun & Malaysia & Thailand & Indonesia & Filipina \\
\hline $\begin{array}{c}2016 \\
\text { (April) }\end{array}$ & 2.846 & 1.819 & 680 & 292 \\
\hline 2015 & 15.741 & 9.036 & 4.136 & 1.884 \\
\hline 2014 & 18.747 & 10.073 & 3.759 & 1.670 \\
\hline 2013 & 16.625 & 9.681 & 3.317 & 1.645 \\
\hline 2012 & 14.833 & 9.154 & 2.391 & 1.456 \\
\hline 2011 & 11.810 & 7.843 & 1.757 & 1.309 \\
\hline 2010 & 8.820 & 7.686 & 1.596 & 1.189 \\
\hline
\end{tabular}

Sumber: Web of Science 


\section{KAJIAN PUSTAKA \\ Manajemen Sumber Daya Manusia}

Manajemen sumber daya manusia sangat penting bagi perusahaan dalam mengelola, mengatur, dan memanfaatkan pegawai sehingga dapat berfungsi secara produktif untuk tercapainya tujuan perusahaan Manajemen sumber daya manusia (MSDM) menurut Dessler (2015) adalah proses untuk memperoleh, melatih menilai dan memberikan kompensasi kepada karyawan dan untuk mengurus relasi kerja mereka, serta hal-hal yang berhubungan dengan keadilan. MSDM dapat didefinisikan sebagai suatu pengelolaan dan perdayagunaan seumber daya yang ada pada individu (pegawai), pengelolaan dan pendayagunaan tersebut dikembangkan secara maksimal di dalam kerja untuk mencapai tujuan organisasi dan pegembangan individu pegawai.

\section{Knowledge Management (Manajemen Pengetahuan)}

Menurut Davidson \& Voss dalam Setiarso et al (2012), Knowledge Management adalah bagaimana orang-orang dari berbagai tempat yang berbeda mulai saling berbicara. Sedangkan Horwitch dan Armacost dalam manajemen pengetahuan sebagai pelaksanaan penciptaan, penagkapan, pentransferan, dan oengaksesan pengetahuan dan informasi yang tepat ketika dibutuhkan untuk membuat keputusan yang lebih baik, bertindak dengan tepat, serta memberikan hasil dalam rangka mendukung strategi bisnis.

Proses knowledge management menurut Probst et al dalam Tobing (2011)

a. Knowledge Identification : proses yang dilakukan dalam menunjukkan lokasilokasi pengetahuan dan pemiliknya secara transparan kepada seluruh angota organisasi.

b. Knowledge Acquisition: proses penyediaan knowledge, skill, expertis yang berasal dari luar organisasi.

c. Knowledge Development: proses yag dilakukan dalam membangun kepakaran dan kapabilitas baru yang belum dimiliki di dalam maupun di luar.

d. Knowledge Sharing/Distribution : Proses yang dilakukan untuk menyebarkan knowledge dengan cara, waktu dan kepada orang yang tepat.

e. Knowledge Utilization: proses dilakukan untuk mendorong dan memfasilitasi organisasi untuk memanfaatkan knowledge yang sudah dimiliki.

f. Knowledge Retention: proses seleksi,

\begin{abstract}
penyimpanan dan pemuktahiran knowledge dan expertis agar dapat dimanfaatkan pada masa mendatang.
\end{abstract}

\section{Knowledge Sharing}

Knowledge sharing menurut Raskov dalam Tobing (2011), knowledge sharing terjadi antar individu dalam suatu kelompok, dimana individu tersebut saling berinteraksi dan bebagi pengetahuan denganindividu lainnya melalui tatap muka ataupun tidak. Menurut Alawi (2007), "knowledge sharing (knowledge transfer) requires that an individual or a group cooperate with others to share knowledge and achieve mutual benefit". Van den Hooff \&Ridder (2004) membagi knowledge sharing terdiri dari dua proses, yakni :

a. Knowledge donating: mengkomunikasikan pengetahuan yang dimiliki kepada orang lain atau individu lainnya.

b. Knowledge collecting: berkonsultasi dan berdiskusi dengan rekan kerja lainnya untuk mendapatkan pengetahuan dari mereka.

\section{Budaya Organisasi}

Robbins (2008) menjelaskan bahwa budaya organisasi merupakan sebuah sistem yang diterima bersama dan dianut oleh para anggota dan sistem tersebut membedakan suatu organisasi dari organisasi-organisasi lainnya. Menurut Gupta et al, dalam Tobing (2011), budaya organisasi yang dapat mendukukung knowledge sharing terdapat enam kategori utama, yaitu: sistem informasi, SDM, proses, kepemimpinan, sistem penghargaan, dan strukur organisasi.

\section{METODE PENELITIAN}

Dalam melaksanakan penelitan ini, penulis menggunakan studi kausal. Berdasarkan jenis informasi yang dikelola, penelitian ini merupakan penelitian kuntitatif. Dalam penelitian ini yang menjadi populasi adalah seluruh dosen tetap pada Perguruan Tinggi Negeri di Kota Bandung, yaitu berjumlah 5.927 orang. Untuk penelitian ini digunakan sampel probabilitas dengan teknik proportional stratified random sampling. Penulis menentukan sampel dengan metode acak sederhana, di mana penulis membagi setiap perguruan tinggi dan memilih sampel tersebut dengan cara acak atau dosen yang ada 
di tempat dan bersedia untuk mengis kuesioner penelitian. Ukuran sampel (jumlah responden) ditentukan dengan menggunakan Metode Slovin. Diperoleh jumlah sampel pada penelitian ini adalah 119 responden. Untuk jumlah elemen setiap sub populasi yang berbeda, maka dicari dahulu sampel fraksinya (fi) dengan cara jumlah subpopulasi dibagi dengan total populasi yang ada kemudian dicari nilai sampel yang diambil dengan cara nilai fi dikalikan dengan jumlah total sampel yang ada, hasilnya dapat dilihat pada Tabel 3

Tabel 3

Proportional Stratified Random Sampling

\begin{tabular}{|l|l|c|c|c|}
\hline No. & $\begin{array}{l}\text { Sub populasi } \\
\text { (berdasarkan } \\
\text { perguruan } \\
\text { tinggi) }\end{array}$ & $\begin{array}{c}\text { Jumlah } \\
\text { elemen } \\
\text { dosen } \\
\text { tetap }\end{array}$ & $\begin{array}{c}\text { Nilai } \\
\text { (fi) }\end{array}$ & $\begin{array}{c}\text { Sample } \\
\text { yang } \\
\text { diambil }\end{array}$ \\
\hline 1. & $\begin{array}{l}\text { Universitas } \\
\text { Pendidikan } \\
\text { Indonesia }\end{array}$ & 1235 & 0,20 & 25 \\
\hline 2. & $\begin{array}{l}\text { Universitas } \\
\text { Padjajaran }\end{array}$ & 1921 & 0,32 & 39 \\
\hline 3. & $\begin{array}{l}\text { Institut } \\
\text { Teknologi } \\
\text { Bandung }\end{array}$ & 1427 & 0.24 & 29 \\
\hline 4. & $\begin{array}{l}\text { Universitas } \\
\text { Islam Bandung, }\end{array}$ & 461 & 0.07 & 9 \\
\hline 5. & $\begin{array}{l}\text { Politeknik } \\
\text { Manufaktur } \\
\text { Bandung }\end{array}$ & 98 & 0.01 & 2 \\
\hline 6. & $\begin{array}{l}\text { Politeknik } \\
\text { Negeri } \\
\text { Bandung }\end{array}$ & 498 & 0.08 & 10 \\
\hline 7. & $\begin{array}{l}\text { Sekolah Tinggi } \\
\text { Pariwisata } \\
\text { Bandung }\end{array}$ & 125 & 0.02 & 2 \\
\hline 8. & $\begin{array}{l}\text { Institut Seni } \\
\text { Budaya } \\
\text { Indonesia } \\
\text { Bandung }\end{array}$ & 162 & 0.02 & 3 \\
\hline JUH & 5927 & 1,000 & 119 \\
\hline & & & \\
\hline
\end{tabular}

Untuk menjabarkan sub-variabel dan item dari variabel yang akan menjadi bahan kuisioner, akan dijabarkan pada Tabel 4.:

Tabel 4

Variabel Operasional

\begin{tabular}{|l|l|}
\hline \multicolumn{1}{|c|}{ Variabel } & \multicolumn{1}{c|}{ Indikator } \\
\hline Struktur Organisasi & Partisipasi \\
\cline { 2 - 2 }$\left(\mathrm{X}_{1}\right)$ & $\begin{array}{l}\text { Jaringan informasi } \\
\text { komprehensif }\end{array}$ \\
\cline { 2 - 2 } & Tim lintas fungsional \\
\hline
\end{tabular}

\begin{tabular}{|l|l|}
\hline \multicolumn{1}{|c|}{ Variabel } & \multicolumn{1}{c|}{ Indikator } \\
\hline Sistem Informasi $\left(\mathrm{X}_{2}\right)$ & Keberedaan teknologi \\
\cline { 2 - 2 } & Kemudahan penggunaan \\
\cline { 2 - 2 } & Kenyamana penggunaan \\
\hline \multirow{4}{*}{ SDM $\left(\mathrm{X}_{3}\right)$} & Motivasi \\
\cline { 2 - 2 } & Kepercayaan \\
\cline { 2 - 2 } $\begin{array}{l}\text { Sistem Penghargaan } \\
\left(\mathrm{X}_{4}\right)\end{array}$ & Komunikasi \\
\cline { 2 - 2 } & Keberadaan penghargaan \\
\cline { 2 - 2 } & Kelayakan penghargaan \\
\hline \multirow{5}{*}{ Kepemimpinan $\left(\mathrm{X}_{5}\right)$} & Penghargaan kelompok \\
\cline { 2 - 2 } & Keterlibatan \\
\cline { 2 - 2 } & Pemahaman \\
\cline { 2 - 2 } & Peresiasi \\
\hline \multirow{3}{*}{ Proses $\left(\mathrm{X}_{6}\right)$} & Pedomanan kerja \\
\cline { 2 - 2 } & Prosedur aktivitas \\
\cline { 2 - 2 } & Aturan bekerja \\
\hline Knowledge Sharing $(\mathrm{Y})$ & Knowledge donating \\
\cline { 2 - 2 } & Knowledge collecting \\
\hline
\end{tabular}

Tabel 5

Persentase Kategori Budaya Organisasi dan Knowledge Sharing

\begin{tabular}{|c|c|c|c|}
\hline No. & Persentase & $\begin{array}{c}\text { Kategori } \\
\text { Budaya } \\
\text { Organisai }\end{array}$ & $\begin{array}{c}\text { Kategori } \\
\text { Knowledge } \\
\text { Sharing }\end{array}$ \\
\hline 1. & $25 \%-43,75 \%$ & $\begin{array}{c}\text { Sangat } \\
\text { Lemah }\end{array}$ & $\begin{array}{c}\text { Sangat } \\
\text { Rendah }\end{array}$ \\
\hline 2. & $>43,75 \%-62,50 \%$ & Lemah & Rendah \\
\hline 3. & $>62,50 \%-81,25 \%$ & Kuat & Tinggi \\
\hline 4. & $>81,25 \%-100 \%$ & Sangat kuat & Sangat Tinggi \\
\hline
\end{tabular}

Struktur: $\mathrm{Y}=\rho \mathrm{YX} 1 \mathrm{X} 1+\rho \mathrm{YX} 2 \mathrm{X} 2+\rho \mathrm{YX} 2 \mathrm{X} 3$

$+\rho \mathrm{YX} 2 \mathrm{X} 4+\rho \mathrm{YX} 2 \mathrm{X} 5+\rho \mathrm{YX} 2 \mathrm{X} 6+\varepsilon$

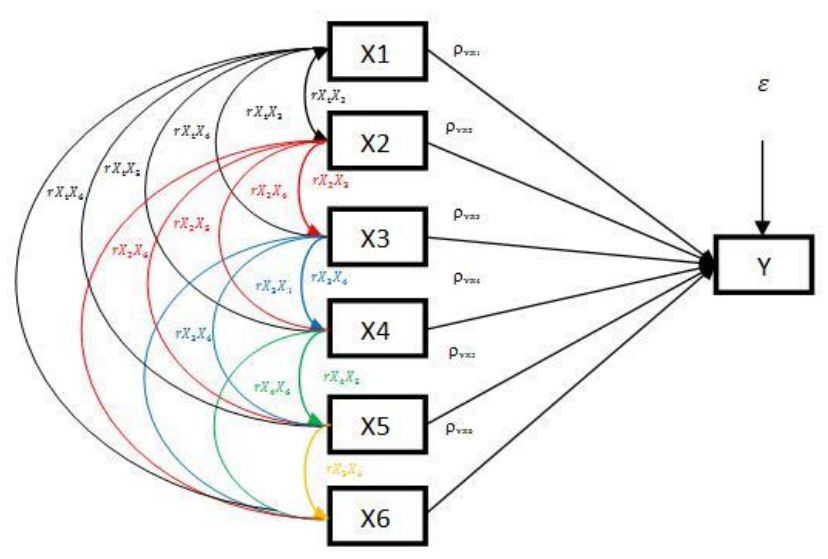

Gambar 2

Model Diagram Jalur 
Keterangan :

Variabel penyebab/eksogenus

$\mathrm{X} 1$ = Struktur Organisasi

$\mathrm{X} 2$ = Sistem Informasi

$\mathrm{X} 3=\mathrm{SDM}$

$\mathrm{X} 4=$ Sistem Penghargaan

$\mathrm{X} 5=$ Kepemimpinan

$\mathrm{X} 6=$ Proses

$\mathrm{Y}=$ Knowledge Sharing

\section{HASIL DAN PEMBAHASAN}

Responden yang menjadi subjek penelitian ini adalah dosen tetap pada Perguruan Tinggi Negeri di Kota Bandung. Karateristik responden terdiri dari jenis kelamin, Pendidikan dan masa kerja. Karakteristik responden dilihat pada tabel 6:

Tabel 6

Karakteristik Responden

\begin{tabular}{|c|c|c|}
\hline Karakteristik & Jumlah & Persentase \\
\hline $\begin{array}{l}\text { Gender } \\
\text { Laki-Laki } \\
\text { Perempuan }\end{array}$ & $\begin{array}{l}66 \\
53\end{array}$ & $\begin{array}{l}55 \% \\
45 \%\end{array}$ \\
\hline Total & 119 & $100 \%$ \\
\hline $\begin{array}{l}\text { Usia } \\
\leq 30 \text { tahun } \\
>31-35 \text { tahun } \\
>35-40 \text { tahun } \\
>40-45 \text { tahun } \\
>45-50 \text { tahun } \\
>50 \text { tahun }\end{array}$ & $\begin{array}{l}10 \\
22 \\
29 \\
18 \\
19 \\
21\end{array}$ & \begin{tabular}{|c|}
$8 \%$ \\
$19 \%$ \\
$24 \%$ \\
$15 \%$ \\
$16 \%$ \\
$18 \%$
\end{tabular} \\
\hline Total & 119 & $100 \%$ \\
\hline $\begin{array}{l}\text { Pendidikan } \\
\text { S2 } \\
\text { S3 }\end{array}$ & $\begin{array}{l}88 \\
31\end{array}$ & $\begin{array}{l}74 \% \\
26 \%\end{array}$ \\
\hline Total & 119 & $100 \%$ \\
\hline $\begin{array}{l}\text { Masa Kerja } \\
\leq 3 \text { tahun } \\
>3-5 \text { tahun } \\
>5-10 \text { tahun } \\
>10-15 \text { tahun } \\
>15 \text { tahun }\end{array}$ & $\begin{array}{c}6 \\
19 \\
40 \\
11 \\
43\end{array}$ & $\begin{array}{c}5 \% \\
16 \% \\
34 \% \\
9 \% \\
36 \%\end{array}$ \\
\hline Total & 119 & $100 \%$ \\
\hline
\end{tabular}

Hasil penelitian pada tabel di atas menunjukkan bahwa 55\% adalah laki-laki dan $45 \%$ perempuan. Karakteristik usia menunjukkan bahwa mayoritas $24 \%$ berusia 35 - 40 tahun, hal ini menunjukkan bahwa sebagian dari responden merupakan usia produktif. Mayoritas sebagian dosen 34\% memiliki masa kerja $>5-10$ tahun tahun dan $36 \%$ memiliki masa kerja > 15 tahun. Selanjutnya, hasil analisis. Karakteristik responden berdasarkan tingkat Pendidikan dapat diketahui bahwa latar belakang pendidikan dosen sebagian besar adalah $74 \%$ berpendidikan terakhir S2.

Tabel 7

Analisis Deskripsi Variabel

\begin{tabular}{cc}
\hline Variabel & $\%$ \\
\hline Struktur Organisasi & 77 (Kuat) \\
Sistem Informasi & 65 (Kuat) \\
SDM & 79 (Kuat) \\
Sistem Penghargaan & 67 (Kuat) \\
Kepemimpinan & 69 (Kuat) \\
Proses & 74 (Kuat) \\
Knowledge Sharing & 88 (Sangat Tinggi) \\
\hline
\end{tabular}

\section{Analisis Korelasi}

Analisis korelasi bertujuan untuk menguji ada tidaknya hubungan antara variable yang satu dengan variable yang lain, (Sarjono \& Julianita, 2011:85). Berikut hasil uji korelasi dalam penelitian:

Tabel 8

Analisis Korelasi Variabel Budaya Organisasi terhadap Knowledge Sharing

\begin{tabular}{lcc}
\hline \multicolumn{1}{c}{ Variabel } & Nilai r & Kesimpulan \\
\hline $\begin{array}{l}\text { Struktur_Organisasi } \\
\left(\mathrm{X}_{1}\right)\end{array}$ & 0,532 & Cukup Kuat \\
Sistem_Informasi $\left(\mathrm{X}_{2}\right)$ & 0,452 & Cukup Kuat \\
SDM $\left(\mathrm{X}_{3}\right)$ & 0,632 & Kuat \\
Sistem_Penghargaan & 0,445 & Cukup Kuat \\
$\left(\mathrm{X}_{4}\right)$ & & \\
Kepemimpinan $\left(\mathrm{X}_{5}\right)$ & 0,472 & Cukup Kuat \\
Proses $\left(\mathrm{X}_{6}\right)$ & 0,416 & Cukup Kuat
\end{tabular}

Jika melihat kesimpulan hasil korelasi, hubungan antara variable bebas terhadap variable terikat didominasi oleh korelasi yang cukup kuat, terdapat satu korelasi yang berada pada kriteria kuat, yaitu hubungan antara variable $\mathrm{SDM}\left(\mathrm{X}_{3}\right)$ terhadap knowledge sharing (Y).

\section{Hasil Uji Secara Simultan}

Berikut hasil perhitungan $\mathrm{R}$ kuadrat $\left(\mathrm{r}^{2}\right)$ yang menggambarkan kecocokan model penelitian, dapat dilihat pada tabel berikut: 
Tabel 9

Model Summary

\begin{tabular}{|c|l|c|c|c|}
\hline Model & R & R Square & $\begin{array}{l}\text { Adjusted } \\
\text { Square }\end{array}$ & $\begin{array}{l}\text { Std. Error of the } \\
\text { Estimate }\end{array}$ \\
\hline 1 & $.664^{\mathrm{a}}$ & .441 & .411 & .35476 \\
\hline
\end{tabular}

a. Predictors: (Constant), Proses, Sistem_Informasi, Struktur_Organisasi, Sistem_Penghargaan, Kepemimpinan, SDM

b. Dependent Variable: Knowledge_Sharing

Besarnya angka R kuadrat (r2) adalah 0,441. Nilai $\mathrm{R}$ kuadrat digunakan untuk mengukur pengaruh struktur organisasi, sistem informasi, SDM, sistem penghargaan, kepemimpinan, dan proses terhadap knowledge sharing dengan rumus sebagai berikut.

$\mathrm{KD}=\mathrm{r} 2 \times 100 \%$

$\mathrm{KD}=0,441 \times 100 \%$

$\mathrm{KD}=44,1 \%$

Artinya pengaruh struktur organisasi, sistem informasi, SDM, sistem penghargaan, kepemimpinan, dan proses terhadap knowledge sharing secara gabungan adalah $44,1 \%$. Sedangkan sisanya $55,9 \% \quad(100 \%$ $44,1 \%$ ) dipengaruhi oleh faktor lain.

Berikut hasil perhitungan uji $F$ yang menggambarkan pengaruh secara simultan antara variabel struktur organisasi, sistem penghargaan, kepemimpinan, SDM, dan proses terhadap knowledge sharing, sebagai berikut:

Tabel 10

\begin{tabular}{|l|l|c|c|c|c|c|}
\hline \multicolumn{7}{|c|}{ Uji ANOVA } \\
\hline \multicolumn{1}{|c|}{ Model } & $\begin{array}{c}\text { Sum of } \\
\text { Squares }\end{array}$ & df & $\begin{array}{c}\text { Mean } \\
\text { Square }\end{array}$ & F & Sig. \\
\hline 1 & Regression & 11.135 & 6 & 1.856 & 14.746 & $.000^{\mathrm{b}}$ \\
\cline { 2 - 7 } & Residual & 14.096 & 112 & .126 & & \\
\cline { 2 - 7 } & Total & 25.231 & 118 & & & \\
\hline \begin{tabular}{l} 
a. Dependent Variable: Knowledge_Sharing \\
\hline
\end{tabular} \\
$\begin{array}{l}\text { b. Pruktur_Organisasi, } \\
\text { Kepemimpinan, SDM }\end{array}$ \\
\hline
\end{tabular}

Dari hasil perhitungan didapat Fhitung $(14,746)>$ Ftabel $(2,19)$ dan $\operatorname{sig} \mathrm{f}=0,000<\alpha$ $=0,05$ maka $\mathrm{H} 0$ ditolak dan $\mathrm{H} 1$ diterima. Berdasarkan hasil perhitungan di atas dapat disimpulkan bahwa variabel struktur organisasi $\left(\mathrm{X}_{1}\right)$, sistem informasi $\left(\mathrm{X}_{2}\right), \mathrm{SDM}$ $\left(\mathrm{X}_{3}\right)$, sistem penghargaan $\left(\mathrm{X}_{4}\right)$, kepemimpinan $\left(\mathrm{X}_{5}\right)$, dan proses $\left(\mathrm{X}_{6}\right)$ secara bersama-sama berpengaruh signifikan terhadap knowledge sharing (Y).

\section{Hasil Uji Secara Parsial}

Tabel 11

Uji Secara Parsial

Coefficients $^{\mathrm{a}}$

\begin{tabular}{|c|c|c|c|c|c|}
\hline \multirow[b]{2}{*}{ Model } & \multicolumn{2}{|c|}{$\begin{array}{c}\text { Unstandardizec } \\
\text { Coefficients }\end{array}$} & \multirow[t]{2}{*}{$\begin{array}{c}\text { Standardized } \\
\text { Coefficients }\end{array}$} & \multirow[t]{2}{*}{$\mathrm{t}$} & \multirow[t]{2}{*}{ Sig. } \\
\hline & B & $\begin{array}{l}\text { Std. } \\
\text { Error }\end{array}$ & & & \\
\hline (Constant) & 1.706 & .220 & & 7.772 & .000 \\
\hline $\begin{array}{l}\text { Struktur_- } \\
\text { Organisasi }\end{array}$ & .111 & .062 & .184 & 1.799 & .075 \\
\hline $\begin{array}{l}\text { Sistem } \\
\text { Informasi }\end{array}$ & .003 & .053 & .007 & .060 & .952 \\
\hline SDM & .396 & .123 & .465 & 3.226 & .002 \\
\hline $\begin{array}{l}\text { Sistem_- } \\
\text { Pengharga } \\
\text { an }\end{array}$ & .073 & .063 & .128 & 1.166 & .246 \\
\hline $\begin{array}{l}\text { Kepemim } \\
\text { pinan }\end{array}$ & -.061 & .071 & -.109 & -.865 & .389 \\
\hline Proses & .058 & .049 & . 100 & 1.191 & .236 \\
\hline
\end{tabular}

a. Dependent Variable: Knowledge_Sharing

$$
\begin{aligned}
& \text { py } \varepsilon 1=\sqrt{1-R^{2}} \\
& =\sqrt{1-0,441} \\
& =0,747
\end{aligned}
$$

Model persamaan struktural analisis jalur model trimming adalah sebagai berikut :

$$
\begin{aligned}
& \hat{Y}=\rho y x_{1} X_{1}+\rho y x_{2} X_{2}+\rho y x_{3} X_{3}+\rho y x_{4} X_{4}+\rho y x_{5} X_{5}+\rho y x_{6} X_{6}+\rho y \varepsilon 1 \\
& \hat{Y}=0,184 X_{1}+0,007 X^{2}+0,465 X_{3}+0,128 X^{4}+(-0,109) X_{5}+0,100 X_{6}+0,747 \varepsilon 1
\end{aligned}
$$

\section{Hasil Hipotesis}

Untuk mengetahui hipotesis hasil dari pengolahan data yang telah dilakukan sebelumnya dapat dilihat pada tabel berikut. 
Tabel 12

Hasil Hipotesis

\begin{tabular}{|c|c|c|}
\hline Hipotesis & Kesimpulan & Artinya \\
\hline $\begin{array}{l}\text { Budaya } \\
\text { Organisasi } \\
\text { berpengaruh } \\
\text { signifikan } \\
\text { terhadap } \\
\text { knowledge } \\
\text { sharing }\end{array}$ & $\begin{array}{l}\mathrm{H}_{0} \text { ditolak } \\
\text { dan } \mathrm{H}_{1} \\
\text { diterima }\end{array}$ & $\begin{array}{l}\text { Semakin kuat } \\
\text { budaya organisasi, } \\
\text { semakin tinggi } \\
\text { implementasi } \\
\text { knowledge } \\
\text { sharing }\end{array}$ \\
\hline $\begin{array}{l}\text { Struktur } \\
\text { organisasi } \\
\text { tidak } \\
\text { berpengaruh } \\
\text { signifikan } \\
\text { terhadap } \\
\text { knowledge } \\
\text { sharing }\end{array}$ & $\begin{array}{l}\mathrm{H}_{0} \text { diterima } \\
\text { dan } \mathrm{H}_{1} \\
\text { ditolak }\end{array}$ & $\begin{array}{l}\text { Semakin kuat } \\
\text { struktur organisasi } \\
\text { tidak berpengaruh } \\
\text { signifikan } \\
\text { terhadap } \\
\text { implementasi } \\
\text { knowledge } \\
\text { sharing. }\end{array}$ \\
\hline $\begin{array}{l}\text { Sistem } \\
\text { informasi tidak } \\
\text { berpengaruh } \\
\text { signifikan } \\
\text { terhadap } \\
\text { knowledge } \\
\text { sharing }\end{array}$ & $\begin{array}{l}\mathrm{H}_{0} \text { diterima } \\
\text { dan } \mathrm{H}_{1} \\
\text { ditolak }\end{array}$ & $\begin{array}{l}\text { Semakin kuat } \\
\text { sistem informasi } \\
\text { tidak berpengaruh } \\
\text { signifikan } \\
\text { terhadap } \\
\text { implementasi } \\
\text { knowledge } \\
\text { sharing. }\end{array}$ \\
\hline $\begin{array}{l}\text { SDM } \\
\text { berpengaruh } \\
\text { signifikan } \\
\text { terhadap } \\
\text { knowledge } \\
\text { sharing }\end{array}$ & $\begin{array}{l}\mathrm{H}_{0} \text { ditolak } \\
\text { dan } \mathrm{H}_{1} \\
\text { diterima }\end{array}$ & $\begin{array}{l}\text { Semakin kuat } \\
\text { SDM, semakin } \\
\text { tinggi } \\
\text { implementasi } \\
\text { knowledge } \\
\text { sharing }\end{array}$ \\
\hline $\begin{array}{l}\text { Sistem } \\
\text { penghargaan } \\
\text { tidak } \\
\text { berpengaruh } \\
\text { signifikan } \\
\text { terhadap } \\
\text { knowledge } \\
\text { sharing }\end{array}$ & $\begin{array}{l}\mathrm{H}_{0} \text { diterima } \\
\text { dan } \mathrm{H}_{1} \\
\text { ditolak }\end{array}$ & $\begin{array}{l}\text { Semakin sistem } \\
\text { penghargaan tidak } \\
\text { berpengaruh } \\
\text { signifikan } \\
\text { terhadap } \\
\text { implementasi } \\
\text { knowledge } \\
\text { sharing. }\end{array}$ \\
\hline $\begin{array}{l}\text { Kepemimpina } \\
\mathrm{n} \quad \text { tidak } \\
\text { berpengaruh } \\
\text { signifikan } \\
\text { terhadap } \\
\text { knowledge } \\
\text { sharing }\end{array}$ & $\begin{array}{l}\mathrm{H}_{0} \text { diterima } \\
\text { dan } \mathrm{H}_{1} \\
\text { ditolak }\end{array}$ & $\begin{array}{l}\text { Semakin kuat } \\
\text { kepemimpinan } \\
\text { tidak berpengaruh } \\
\text { signifikan } \\
\text { terhadap } \\
\text { implementasi } \\
\text { knowledge } \\
\text { sharing. }\end{array}$ \\
\hline $\begin{array}{l}\text { Proses tidak } \\
\text { berpengaruh } \\
\text { signifikan } \\
\text { terhadap }\end{array}$ & $\begin{array}{l}\mathrm{H}_{0} \text { diterima } \\
\text { dan } \mathrm{H}_{1} \\
\text { ditolak. }\end{array}$ & $\begin{array}{l}\text { Semakin kuat } \\
\text { proses tidak } \\
\text { berpengaruh } \\
\text { signifikan }\end{array}$ \\
\hline
\end{tabular}

\begin{tabular}{|l|l|l|}
\hline \multicolumn{1}{|c|}{ Hipotesis } & Kesimpulan & \multicolumn{1}{c|}{ Artinya } \\
\hline $\begin{array}{l}\text { knowledge } \\
\text { sharing }\end{array}$ & & terhadap \\
& & implementasi \\
& & knowledge \\
& & sharing. \\
\hline
\end{tabular}

Tabel 13

Besar Pengaruh Langsung Variabel Budaya Organisasi Terhadap Knowledge Sharing

\begin{tabular}{|c|c|c|}
\hline Variabel & Koef. Jalur & $\begin{array}{c}\text { Lang } \\
\text { sung }\end{array}$ \\
\hline Struktur Organisasi $\left(\mathrm{X}_{1}\right)$ & 0,184 & 0,034 \\
\hline Sistem Informasi $\left(\mathrm{X}_{2}\right)$ & 0,007 & 0,001 \\
\hline SDM $\left(\mathrm{X}_{3}\right)$ & 0,465 & 0,216 \\
\hline Sistem Penghargaan $\left(\mathrm{X}_{4}\right)$ & 0,128 & 0,016 \\
\hline $\begin{array}{c}\text { Kepemim } \\
\text { pinan }\left(\mathrm{X}_{5}\right)\end{array}$ & $-0,109$ & 0,012 \\
\hline Proses $\left(\mathrm{X}_{6}\right)$ & 0,049 & 0,01 \\
\hline
\end{tabular}

Tabel 14

Besar Pengaruh Tidak Langsung Variabel Budaya Organisasi Terhadap Knowledge Sharing

\begin{tabular}{|c|c|c|c|c|c|c|}
\hline \multirow{2}{*}{ Variabel } & \multicolumn{7}{|c|}{ Tidak Langsung } \\
\cline { 2 - 7 } & $\mathrm{X}_{1}$ & $\mathrm{X}_{2}$ & $\mathrm{X}_{3}$ & $\mathrm{X}_{4}$ & $\mathrm{X}_{5}$ & $\mathrm{X}_{6}$ \\
\hline $\begin{array}{c}\text { Struktur } \\
\text { Organisasi }\left(\mathrm{X}_{1}\right)\end{array}$ & - & 0,001 & 0,055 & 0,012 & $-0,012$ & 0,008 \\
\hline $\begin{array}{c}\text { Sistem } \\
\text { Informasi }\left(\mathrm{X}_{2}\right)\end{array}$ & 0,001 & - & 0,002 & 0,001 & $-0,001$ & 0,001 \\
\hline SDM $\left(\mathrm{X}_{3}\right)$ & 0,056 & 0,002 & - & 0,033 & $-0,036$ & 0,023 \\
\hline $\begin{array}{c}\text { Sistem } \\
\text { Penghargaan } \\
\left(\mathrm{X}_{4}\right)\end{array}$ & 0,013 & 0,001 & 0,033 & - & $-0,010$ & 0,005 \\
\hline $\begin{array}{c}\text { Kepemim } \\
\text { pinan }\left(\mathrm{X}_{5}\right)\end{array}$ & $-0,013$ & $-0,000$ & $-0,036$ & $-0,010$ & - & $-0,005$ \\
\hline Proses $\left(\mathrm{X}_{6}\right)$ & 0,010 & 0,000 & 0,023 & 0,005 & $-0,005$ & - \\
\hline
\end{tabular}

Tabel 15

Total Pengaruh Variabel Budaya Organisasi Terhadap Knowledge Sharing

\begin{tabular}{|c|c|}
\hline Variabel & Total \\
\hline Struktur Organisasi $\left(\mathrm{X}_{1}\right)$ & 0,110 \\
\hline Sistem Informasi $\left(\mathrm{X}_{2}\right)$ & 0,004 \\
\hline SDM $\left(\mathrm{X}_{3}\right)$ & 0,330 \\
\hline Sistem Penghargaan $\left(\mathrm{X}_{4}\right)$ & 0,068 \\
\hline Kepemimpinan $\left(\mathrm{X}_{5}\right)$ & 0,012 \\
\hline Proses $\left(\mathrm{X}_{6}\right)$ & 0,047 \\
\hline
\end{tabular}

Berdasarkan hasil analisis terhadap pengolahan data dalam penelitian ini, dapat ditarik beberapa kesimpulan sebagai berikut:

1. Struktur organisasi, sistem informasi, SDM, sistem penghargaan, kepemimpinan, proses 
dalam kategori kuat. Sehingga dapat dikatakan budaya organisais pada perguruan tinggi negeri di Kota Bandung telah mendukung implementasi knowledge sharing

2. Knowledge sharing dalam kategori Tinggi, sehingga dapat dikatakan dosen pada perguruan tinggi negeri di Kota Bandung telah melakukan proses sharing pengetahuan dengan sangat baik.

3. Struktur organisasi tidak berpengaruh signifikan terhadap knowledge sharing. Semakin kuat struktur organisasi tidak berpengaruh signifikan terhadap implementasi knowledge sharing pada dosen di perguruan tinggi di Kota Bandung.

4. Sistem informasi tidak berpengaruh signifikan terhadap knowledge sharing. Semakin kuat sistem informasi tidak berpengaruh signifikan terhadap implementasi knowledge sharing pada dosen di perguruan tinggi di Kota Bandung.

5. SDM berpengaruh signifikan terhadap knowledge sharing. Semakin kuat SDM, semakin tinggi implementasi knowledge sharing pada dosen di perguruan tinggi di Kota Bandung.

6. Sistem penghargaan tidak berpengaruh signifikan terhadap knowledge sharing Semakin sistem penghargaan tidak berpengaruh signifikan terhadap implementasi knowledge sharing pada dosen di perguruan tinggi di Kota Bandung.

7. Kepemimpinan tidak berpengaruh signifikan terhadap knowledge sharing. Semakin kuat kepemimpinan tidak berpengaruh signifikan terhadap implementasi knowledge sharing pada dosen di perguruan tinggi di Kota Bandung.

8. Proses tidak berpengaruh signifikan terhadap knowledge sharing. Semakin kuat proses tidak berpengaruh signifikan terhadap implementasi knowledge sharing pada dosen di perguruan tinggi di Kota Bandung.

9. Budaya organisasi berpengaruh signifikan terhadap knowledge sharing. Semakin kuat budaya organisasi, semakin tinggi implementasi knowledge sharing pada dosen di perguruan tinggi di Kota Bandung.

\section{KESIMPULAN DAN SARAN}

Berdasarkan hasil analisis terhadap pengolahan data dalam penelitian ini, dapat disimpulkan bahwa budaya organisasi yang terdiri ari dari struktur organisasi, sistem informasi, sumberdaya manusia, sistem penghargaan, kepemimpinan, dan proses pada perguruan tinggi negeri di Kota Bandung telah mendukung implementasi knowledge sharing.

Berdasarkan kesimpulan serta keterbatasn pada penelitin ini, diperoleh saran sebagai berikut: menguji peran faktor budaya organisasi lainnya, menggabungkan metode penelitian kualitatif ke tingkat yang lebih dalam; metode seperti pengamatan kualitatif dan studi longitudinal sangat dianjurkan, serta dalam pemilihan sampel harus dapat meyakinkan responden agar dapat mengisi dengan sejujur-jujurnya, karena indikasi dari hasil penelitian menggambarkan bahwa, jika pernyataan menilai diri sendiri cenderung mengisi dengan jawaban "baik", tetapi jika pernyataan mengenai penilaian organisasi cederung mengisi dengan jawaban "kurang baik", atau dengan cara menambah jumlah sampel. Melakukan penelitian secara mendalam lebih banyak aspek struktur organisasi dan SDM untuk sampai pada pemahaman yang lebih kaya tentang peran budaya organisasi dalam keberhasilan berbagi pengetahuan.

\section{DAFTAR PUSTAKA}

Absah, Yeni. (2009). Pengaruh Pembelajaran Organisasi terhadap Kompetensi, Tingkat Diversifikasi dan Kinerja Perguruan Tinggi Swasta di Sumatera Utara. Vol.6. No.3

Al-Alawi, A. I., Al-Marzooqi, N. Y., \& Mohammed, Y. F. (2007). Organizational culture and knowledge sharing: Critical success factors. Journal of Knowledge Management, 11(2), 22-42. https://doi.org/10.1108/13673270710738 898

Dessler, Gary. (2015). Manajemen Sumber Daya Manusia Edisi 14. Salemba.Jakarta. 
Gorey, R. M., \& Dobat, D. R. (1996). The Sistems Thinker.

Halawi, L. A., Aronson, J. E., Mccarthy, R. V, Halawi, L. A., Aronson, J. E., \& Mccarthy, R. V. (2005). Resource-Based View of Knowledge Management for Competitive Advantage Resource-Based View of Knowledge Management for Competitive Advantage. 3.

Hendriks, P. (1999). Why Share Knowledge? The Influence of ICT on the Motivation for Knowledge Sharing. 6(2), 91-100.

Ipe, M. (2003). Human Resource Development Review. https://doi.org/10.1177/15344843032579 85

Islamy, F. J. (2013). The Influence of Organizational Culture on the Implementation of Knowledge Sharing Lecturers at Bandung Indonesia University of Education. 1-13. Retrieved from

https://www.emeraldinsight.com/doi/abs/ 10.1108/JKM-11-2015-0427

Ricceri, F. (2008). Intellectual Capital and Knowledge Management.

Robbins, Stephen P\& Judge, Timothy A. (2008). Perilaku Organisasi, Edisi Duabelas. Salemba Empat. Jakarta

Sarjono, Haryadi \&Julianita, Winda. (2011). SPSS vs LISREL : Sebuah Pengantar, Aplikasi untuk Riset, Salemba
Empat.Jakarta

Setiarso et al.(2012). Knowledge Managament pada Organisasi. Graha Ilmu. Yogyakarta.

Tobing, Paul L. (2007). Knowledge Management. Graha Ilmu.Yogyakarta.

Tobing, Paul L. (2011). Manajemen Knowledge Sharing Berbasis Komunitas. Knowledge Management Society Indonesia.Bandung.

Uhl-bien, M., Marion, R., \& Mckelvey, B. (2007). Complexity Leadership Theory: Shifting Leadership from The Industrial Age to The Knowledge Era,18, 298-318. https://doi.org/10.1016/j.leaqua.2007.04.0 02

Van den Hooff, B., \& de Leeuw van Weenen, F. (2004). Committed to share: Commitment and CMC use as antecedents of knowledge sharing. Knowledge and Process Management, 11(1), $13-24$. https://doi.org/10.1002/kpm.187

Van Den Hooff, B., \& Ridder, J. A. (2004). Knowledge Sharing in Context: The Influence of Organizational Commitment, Communication Climate and CMC Use on Knowledge Sharing. Journal of Knowledge Management, 8(6), 117-130. https://doi.org/10.1108/13673270410567 675 
Journal IMAGE | Volume 7, Number 1, April 2018, page 29-37 
Journal IMAGE | Volume 7, Number 1, April 2018, page 29-37 
Journal IMAGE | Volume 7, Number 1, April 2018, page 29-37 